\title{
Continuous wound infiltration of ropivacaine for reducing of postoperative pain after anterior lumbar fusion surgery: a clinical retrospective comparative study
}

\author{
Sang-Min Lee ${ }^{1}$, Dong-Ju Yun ${ }^{1}$, Sang-Ho Lee ${ }^{2}$, Hyung-Chang Lee ${ }^{3}$, and Kyung Ho Joeng ${ }^{1}$ \\ 'Department of Neurosurgery, Busan Wooridul Spine Hospital (WSH), Busan, Korea \\ ${ }^{2}$ Department of Neurosurgery, Wooridul Spine Hospital (WSH) Cheongdam, Seoul, Korea \\ ${ }^{3}$ Department of Cardiovascular Surgery, Busan Wooridul Spine Hospital (WSH), Busan, Korea
}

Received October 26, 2020

Revised December 10, 2020

Accepted December 14, 2020

Handling Editor: Jiseok Baik

\section{Correspondence}

Dong-Ju Yun

Department of Neurosurgery, Busan Wooridul Spine Hospital, 1523, Jungangdaero, Dongnae-gu, Busan 47710, Korea Tel: +82-51-559-2000

Fax: +82-51-559-2290

E-mail: djyunns@gmail.com
Background: Local anesthetic infiltration at the site of a surgical wound is commonly used to control postoperative pain. In this study, we examined the effectiveness of continuous local infiltration at an abdominal surgical site in patients undergoing anterior lumbar interbody fusion (ALIF) surgery.

Methods: Sixty-one patients who underwent ALIF surgery were enrolled. For thirtyone of them, a continuous local anesthetics infiltration system was used at the abdominal site. We collected data regarding the patients' sleep quality; satisfaction with pain control after surgery; abilities to perform physical tasks and the additional application of opioids in the postoperative 48 hours.

Results: The On-Q system group showed reduced visual analogue scale scores for pain at the surgical site during rest and movement at 0, 12, 24, and 48 hours; and more was satisfied with pain control management at the first postoperative day (7.0 \pm 1.2 vs. $6.0 \pm 1.4 ; P=0.003)$ and week $(8.1 \pm 1.6$ vs. $7.0 \pm 1.8 ; P=0.010)$ than the control group. The number of additional patient-controlled analgesia (PCA) bolus and pethidine injections was lower in the On-Q group (PCA: $3.67 \pm 1.35$ vs. 4.60 $\pm 1.88 ; P=0.049$ and pethidine: $2.09 \pm 1.07$ vs. $2.73 \pm 1.38 ; P=0.032$ ). Patients who used the On-Q system performed more diverse activity and achieved earlier ambulation than those in the control group.

Conclusions: Continuous wound infiltration with ropivacaine using an On-Q system may be effective for controlling postoperative pain after ALIF surgery.

Key Words: Activities of Daily Living; Analgesia, Patient-Controlled; Anesthesia, Local; Anesthetics, Local; Pain Management; Pain, Postoperative; Ropivacaine; Spinal Fusion; Surgical Wound.

\section{INTRODUCTION}

Local anesthetic infiltration at the site of a surgical wound has become an increasingly common method for controlling postoperative pain [1]. The method is simple, safe, and may reduce the use of opioids, additional complications during perioperative periods, the duration of hospitalization, and costs [2].

However, the effectiveness of local anesthesia infiltration for lumbar spine surgery has been a point of controversy. Kjærgaard et al. [3] reported in a review article that the clinical significance of this method for lumbar (a) This is an open-access article distributed under the terms of the Creative Commons Attribution Non-Commercial License (http://creativecommons.org/licenses/by-nc/4.0/), which permits unrestricted non-commercial use, distribution, and reproduction in any medium, provided the original work is properly cited.

(C) The Korean Pain Society, 2021
Author contributions: Sang-Min Lee: Writing/manuscript preparation; Dong-Ju Yun: Supervision; Sang-Ho Lee: Methodology; Hyung-Chang Lee: Investigation; Kyung Ho Joeng: Writing/manuscript preparation. 
spine surgery was still questionable. In contrast, Perera [4] claimed, in a meta-analysis, that evidence supported the use of intramuscular local anesthetic infiltration to reduce the frequency of analgesics and the time to require first analgesics.

Recently, the number of transabdominal approaches to correct spinal vertebra and discs, such as anterior lumbar interbody fusion (ALIF) and oblique lumbar interbody fusion, has increased [5]. Many articles have reported the effectiveness of local anesthesia infiltration at the surgical site in abdominal surgeries such as colorectal surgery, cholecystectomy, hepatobiliary pancreatic surgery, and caesarean section [6-9]. However, the effectiveness of local anesthetic infiltration at the surgical site in transabdominal spinal surgery remains unknown.

In this study, we examined the effectiveness of local infiltration with ropivacaine at the abdominal surgical site in patients who underwent ALIF surgery.

\section{MATERIALS AND METHODS}

This is a retrospective case control study, which analyzes the effectiveness of continuous local anesthetics at an abdominal surgical site in patients undergoing ALIF. The study design was approved by the Institutional Review Board of Wooridul Spine Hospital (2019-08-WSH-006) in September 2019.

We retrospectively collected data on patients that had undergone ALIF and posterior pedicle screw fixation under three lumbar segmental levels, due to degenerative lumbar spine disease, who visited the hospital between January and June 2019. All the patients in our study had not responded to non-surgical treatments such as medication, physical therapy, and epidural steroid injection for at least 6 months. The exclusion criteria for this study patients include those who had undergone corrective surgery for deformity such as degenerative scoliosis and kyphosis; had cognitive or psychiatric disease; had known allergic reaction to local anesthetics; used opioids for more than 3 months; or had any contraindications for drugs used for pain control. Patients who met the inclusion criteria were divided into two groups: those who used the continuous local anesthetics infiltration system (On-Q system; Halyard Health, Alpharetta, GA) at the abdominal surgical site, and those who did not (control). We explained the On-Q system, including the benefits, risks, goal, and components to all patients undergoing ALIF surgery in our hospital. The patients that used the On-Q system decided to apply this system by themselves.

The On-Q system consists of an indwelling catheter and an elastomeric pump (Fig. 1). At the end of the ALIF pro- cedure, the surgeon placed the multi-holed catheter between the abdominal muscle fascia and subcutaneous fat tissue. After the catheter was placed through the subcutaneous tissue, it was connected to the elastomeric pump filled with $40 \mathrm{~mL}$ of $2 \%$ ropivacaine and $60 \mathrm{~mL}$ of normal saline. The On-Q pump continuously infused $0.8 \%$ ropivacaine at a rate of $2 \mathrm{~mL} / \mathrm{hr}$ through the indwelling catheter for 2 days. All ALIF surgeries and On-Q pump procedures were performed by one surgeon (HC Lee). After these procedures, the patients were turned to a prone position. If posterior decompression was necessary, the surgeon performed a laminotomy on both sides and posterior fixation with percutaneous pedicle screws at the fusion level. If not, the surgeon only performed percutaneous pedicle screw fixation immediately.

The patient-controlled analgesia (PCA) system was filled with fentanyl $800 \mathrm{mg}$ and nefopam hydrochloride $60 \mathrm{mg}$. Its total volume was $100 \mathrm{~mL}$; it was set to infuse $2 \mathrm{~mL} / \mathrm{hr}$ continuously, and deliver $0.5 \mathrm{~mL}$ per bolus dose, with a 15 minute lockout time (Accufuser plus ${ }^{\circledR}$; Woo Young Medical, Jincheon, Korea). Tramadol $37.5 \mathrm{mg}$, acetaminophen $325 \mathrm{mg}$, and muscle relaxants were taken by all patients twice a day during hospitalization. They were also administered pethidine $(25 \mathrm{mg}$ ) for severe pain (above 5 on the visual analogue scale [VAS]).

We collected data regarding pain intensity, as assessed before the operation, upon returning to the recovery room (H0), and at postoperative 12 hours, 24 hours, 48 hours, and 1 week, using a VAS score from 0 (no pain) to 10 (worst pain). We assessed the pain intensity at the abdominal and posterior lumbar surgical sites separately, at rest and during movement (coughing, turning, or walking). The sleep

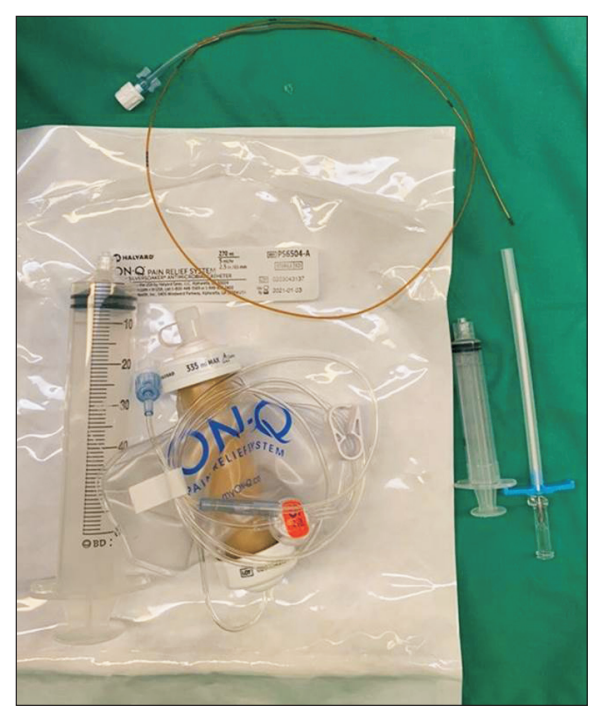

Fig. 1. The components of On-Q system (indwelling catheter and elastic pump, Halyard Health, Alpharetta, GA). 
Table 1. The demographic characters of the patients

\begin{tabular}{|c|c|c|c|}
\hline Variable & On-Q $(n=31)$ & Control $(n=30)$ & $P$ value \\
\hline Age (yr) & $66.7 \pm 8.8$ & $65.5 \pm 9.8$ & 0.595 \\
\hline Male & $21(67.7)$ & $16(53.3)$ & 0.249 \\
\hline $\mathrm{BMI}\left(\mathrm{kg} / \mathrm{m}^{2}\right)$ & $24.9 \pm 2.9$ & $25.4 \pm 3.1$ & 0.528 \\
\hline HTN & $12(38.7)$ & $16(53.3)$ & 0.309 \\
\hline DM & $16(51.6)$ & $14(46.7)$ & 0.999 \\
\hline Cardiovascular disease & $2(6.5)$ & $3(10.0)$ & 0.671 \\
\hline Smoking & $6(19.4)$ & $6(20.0)$ & $>0.999$ \\
\hline \multicolumn{4}{|l|}{ Preoperative pain severity } \\
\hline Back pain & $7.5 \pm 1.3$ & $7.3 \pm 11.5$ & 0.571 \\
\hline Leg pain & $6.2 \pm 1.9$ & $6.8 \pm 1.9$ & 0.271 \\
\hline ASA class $: \mathrm{I} / \mathrm{II}$ & $9 / 22$ & $5 / 25$ & 0.251 \\
\hline Diagnosis & & & 0.695 \\
\hline Central stenosis & $3(9.7)$ & $1(3.3)$ & \\
\hline Foraminal stenosis & $10(32.3)$ & $8(26.7)$ & \\
\hline Lytic spondylolisthesis & $8(25.8)$ & $9(30.0)$ & \\
\hline Degenerative spondylolisthesis & $10(32.3)$ & $12(40.0)$ & \\
\hline Fused level & $1.5 \pm 0.7$ & $1.5 \pm 0.8$ & 0.808 \\
\hline Posterior decompression & $19(61.3)$ & $22(73.3)$ & 0.316 \\
\hline Hospitalization (day) & $18.2 \pm 6.9$ & $18.0 \pm 5.1$ & 0.877 \\
\hline Duration of anesthesia (min) & $312.1 \pm 135.5$ & $309.7 \pm 128.7$ & 0.943 \\
\hline Duration of operation (min) & $189.1 \pm 167.6$ & $252.3 \pm 133.3$ & 0.109 \\
\hline Cristalloids (mL) & $1,537.1 \pm 672.3$ & $1,551.8 \pm 679.0$ & 0.932 \\
\hline Colloid (mL) & $517.7 \pm 106.9$ & $605.0 \pm 181.2$ & 0.025 \\
\hline $\mathrm{EBL}(\mathrm{mL})$ & $477.4 \pm 279.2$ & $494.3 \pm 233.6$ & 0.799 \\
\hline Transfusion & $3(9.7)$ & 7 (23.3) & 0.150 \\
\hline Complication of PCA & $4(12.9)$ & $3(10.0)$ & $>0.999$ \\
\hline
\end{tabular}

Values are presented as mean \pm standard deviation or number (\%).

BMI: body mass index, HTN: hypertension, DM: diabetes mellitus, ASA class: American Society of Anesthesiologist classification, EBL: estimated blood loss, PCA: patients controlled analgesia.

quality of the patients was estimated during the postoperative first and second nights and at 1 week using a numeric rating scale (NRS) from 0 (very poor, not sleeping for even a moment the previous night) to 10 (excellent, best sleep, as good as before the occurrence of pain), so as their satisfaction with the postoperative pain management on the first day, second day, and first week also using an NRS from 0 (no satisfaction) to 10 (excellent satisfaction in regards to pain).

We collected data regarding patients' ability to perform movement tasks with or without assistance, including turning in bed, sitting on the bed, getting out of bed, standing, using the restroom, walking with a walker, walking by themselves, and walking more than 100 meters before the operation and at H0, 12 hours, 24 hours, 48 hours, and 1 week. Assistance with postoperative actions was defined as the state of the patient's need for help from nurses or caregivers in performing their actions. We also recorded the numbers of bolus used with the PCA system and the administrations of pethidine in the postoperative 48 hours.

\section{RESULTS}

During the study period, 61 patients received ALIF surgery. Among them, 31 chose to use the continuous local infiltration system (On-Q group), while the others did not ( $\mathrm{n}=30$, control group). The demographic characteristics of each groups are shown in Table 1. The preoperative diagnoses, fusion levels, and the trials of posterior decompression did not differ significantly between the groups. The severity of preoperative back pain and leg pain was not significantly different between the groups. Among perioperative parameters such as estimated blood loss, duration of operation and anesthesia, transfusion, and the total volume of colloid or crystalloid fluid, only the total volume of colloid was greater in the control group. The operative times of the control group were longer than those of the On-Q group, but the difference was not statistically significant (189.1 \pm 167.6 vs. $252.3 \pm 133.3 ; P=0.109$ ). Because of this, more colloid fluid was used in the control group (517.7 $\pm 106.9 \mathrm{vs}$. $605.0 \pm 181.2 ; P=0.025$, Table 1).

The VAS scores for pain at the surgical site during resting and movement were lower in the $\mathrm{ON}-\mathrm{Q}$ group at $\mathrm{HO}$ 
Table 2. The presentation of pain

\begin{tabular}{lccc}
\hline Severity of pain & On-Q $(\mathrm{n}=31)$ & Control $(\mathrm{n}=30)$ & $P$ value \\
\hline VAS (abdomen, resting) & & \\
Pre OP & 0 & 0 & 0.999 \\
Post OP & $3.7 \pm 2.1$ & $5.1 \pm 1.9$ & 0.010 \\
Post 12 hr & $3.4 \pm 1.9$ & $4.8 \pm 1.9$ & 0.004 \\
Post 24 hr & $2.4 \pm 1.4$ & $3.7 \pm 1.6$ & 0.001 \\
Post 48 hr & $1.7 \pm 1.1$. & $2.6 \pm 1.2$ & 0.005 \\
Post 1 wk & $1.3 \pm 1.0$ & $1.6 \pm 1.0$ & 0.148 \\
VAS (abdomen, activation) & & \\
Pre OP & 0 & 0 & 0.999 \\
Post OP & $4.0 \pm 2.0$ & $5.4 \pm 1.9$ & 0.005 \\
Post 12 hr & $3.7 \pm 1.5$ & $5.3 \pm 1.7$ & $<0.001$ \\
Post 24 hr & $2.4 \pm 1.2$ & $3.7 \pm 1.5$ & $<0.001$ \\
Post 48 hr & $1.7 \pm 1.0$ & $3.0 \pm 1.2$ & $<0.001$ \\
Post 1 wk & $1.2 \pm 0.9$ & $1.6 \pm 1.1$ & 0.115 \\
VAS (back pain, resting) & & \\
Pre OP & $6.2 \pm 1.9$ & $6.7 \pm 1.9$ & 0.271 \\
Post OP & $6.3 \pm 1.7$ & $7.1 \pm 2.3$ & 0.114 \\
Post 12 hr & $5.4 \pm 1.6$ & $5.1 \pm 1.4$ & 0.470 \\
Post 24 hr & $4.1 \pm 1.2$ & $4.3 \pm 1.1$ & 0.582 \\
Post 48 hr & $3.3 \pm 1.4$ & $3.4 \pm 1.4$ & 0.899 \\
Post 1 wk & $2.5 \pm 0.8$ & $2.6 \pm 0.6$ & 0.534 \\
VAS (back pain, activation) & & 0.09 \\
Pre OP & $6.7 \pm 1.3$ & $7.2 \pm 1.4$ & 0.252 \\
Post OP & $6.9 \pm 1.6$ & $7.1 \pm 2.6$ & 0.727 \\
Post 12 hr & $5.3 \pm 1.4$ & $5.5 \pm 2.0$ & 0.631 \\
Post 24 hr & $4.0 \pm 1.0$ & $4.5 \pm 1.6$ & 0.175 \\
Post 48 hr & $3.2 \pm 1.0$ & $3.4 \pm 1.2$ & 0.542 \\
Post 1 wk & $2.4 \pm 0.8$ & $2.7 \pm 0.8$ & 0.139 \\
Quality of sleep & & & \\
Pre OP & $4.5 \pm 1.7$ & $4.6 \pm 2.7$ & 0.838 \\
Post 24 hr & $5.8 \pm 2.0$ & $5.2 \pm 0.6$ & 0.255 \\
Post 48 hr & $6.1 \pm 2.4$ & $6.0 \pm 1.0$ & 0.838 \\
Post 1 wk & $6.8 \pm 2.5$ & $6.7 \pm 1.2$ & 0.783 \\
Satisfaction of pain management & & \\
Pre OP & $1.7 \pm 3.0$ & $2.6 \pm 2.2$ & 0.220 \\
Post 24 hr & $7.0 \pm 1.2$ & $6.0 \pm 1.4$ & 0.003 \\
Post 48 hr & $7.2 \pm 1.1$ & $6.7 \pm 1.5$ & 0.092 \\
Post 1 wk & $8.1 \pm 1.6$ & $7.0 \pm 1.8$ & 0.010 \\
\hline
\end{tabular}

Values are presented as mean \pm standard deviation.

VAS: visual analogue scale, Pre: preoperative, Post: postoperative, OP: operation.

and at 12,24 , and 48 hours. Use of the On-Q system did not affect the intensity of pain at the abdominal lesion 1 week after the operation. The intensity of pain at posterior surgical sites (percutaneous pedicle screw or decompression) was also not affected by use of the On-Q system (Table 2, Fig. 2). Patients in the control group pushed the button on the PCA system for a bolus injection more frequently than those in the On-Q group (3.67 \pm 1.35 vs. $4.60 \pm 1.88 ; P=$ 0.049). The number of injections of pethidine in the On- $Q$ group was lower than that in the control group $(2.09 \pm 1.07$ vs. $2.73 \pm 1.38 ; P=0.032$ ) (Table 3, Fig. 3). The complication rates of the PCA system did not differ significantly between the two groups.

During 1 week of hospitalization, no differences in sleep quality were observed $(P=0.838$ the first day, $P=0.255$ the second night, and $P=0.783$ at postoperative week 1$)$. The patients using the On-Q system were more satisfied with their pain control management on the postoperative first day $(7.0 \pm 1.2$ vs. $6.0 \pm 1.4 ; P=0.003)$ and at 1 week $(8.1 \pm 1.6$ vs. $7.0 \pm 1.8 ; P=0.010)$. On the second postoperative day, patients in the On-Q group were more satisfied with their pain management than those in the control group $(7.2 \pm 1.1$ vs. $6.7 \pm 1.5)$, but the difference was not statistically significant $(P=0.092)$.

The postoperative data regarding activity with assistance showed that patients using the On-Q system were more capable of turning in bed, sitting, standing, and using the restroom, and walked sooner than those in the control group. Patients in the On-Q group also performed the tasks above without assistance sooner than those in the control group (Tables 4, 5).

We reviewed all patients' medical records for 3 months after the operation. There were no reports of complications related to the On-Q system such as local fluid collection, infections, or skin redness at the insertion site.

\section{DISCUSSION}

We investigated the effectiveness of a continuous local infiltration system using ropivacaine at the surgical site in patients who underwent ALIF surgery. Our findings revealed that this system may potentially be used to control postoperative pain.

Relieving postoperative pain has become a major component in the care of patients who have undergone lumbosacral fusion [10]. A study by Hopf et al. [11] revealed that postoperative pain was exacerbated by increasing inflammatory factors in the surrounding tissue and the catecholamine level, resulting in insufficient wound perfusion and circulation. Wound infiltration with local anesthetics alleviates pain and promotes the wound-healing process by increasing perfusion and oxygenation at the surgical site [10].

Another hypothesis is that local continuous anesthesia infiltration reduces postoperative pain via modification of the central nervous system (CNS) [11]. Peripheral tissue damage triggered two types of CNS activation pathway. The first pathway, central sensitization, was activated by nociceptive afferent input due to operative tissue damage. This nociceptive stimulation lead to over-activation of spinal cord neurons. This hyper-activation results in an increase in the postoperative pain response. The other 

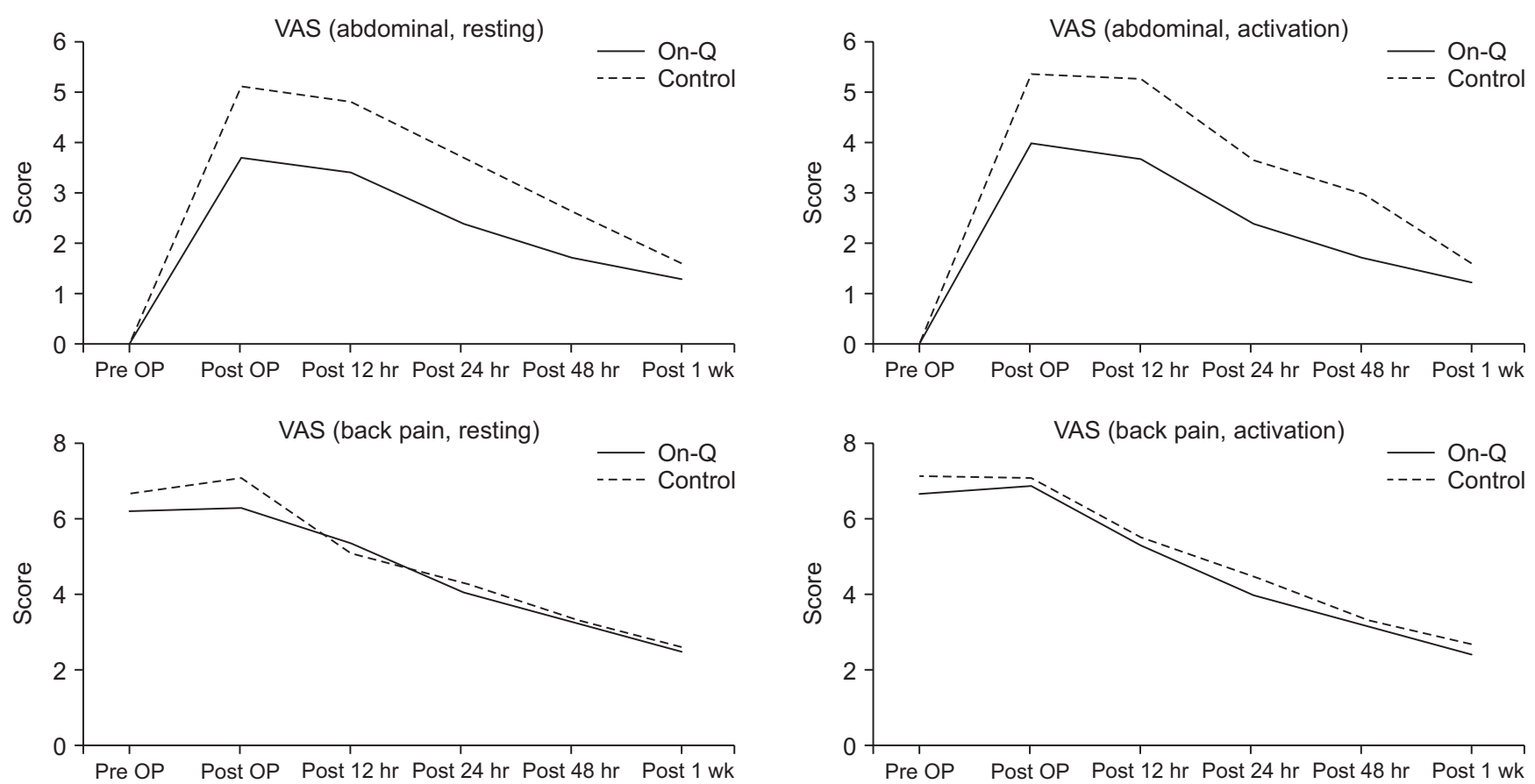

Fig. 2. Visual analoge scale (VAS) score for pain at the abdomanial site and back lesion at postoperative 1 week.

Table 3. The requirements of additional pain control management

\begin{tabular}{lccc}
\hline & On-Q $(n=31)$ & Control $(n=30)$ & $P$ value \\
\hline PCA bolus required & $3.67 \pm 1.35$ & $4.60 \pm 1.88$ & 0.049 \\
Additional pethidine used & $2.09 \pm 1.07$ & $2.73 \pm 1.38$ & 0.032 \\
\hline
\end{tabular}

Values are presented as mean \pm standard deviation.

PCA: patients controlled analgesia.

pathway passed through group $\mathrm{C}$ nerve fibers. The postoperative pain excited the dorsal horn of the spinal cord, and this response increased the severity of the pain. As a result, the wound infiltration of local anesthesia reduced the postoperative pain by increasing perfusions, elevating oxygenation and blocking the central nociceptic pathways along with peripheral C-fibers. The continuous wound infiltration system prolonged these effects for 2 days after surgery.

Ropivacaine is the propyl analogue of bupivacaine. It has a longer duration of action than bupivacaine and also inhibits the inflow of sodium in nerve fibers. Ropivacaine is less lipophilic than bupivacaine, so it has a lower tendency to penetrate large myelinated motor neuron fibers. As such, ropivacaine is used for differential sensory blockage and has fewer side effects involving the CNS and the heart [12].

Local anesthetic infiltration at the surgical wound has long been performed in many surgical fields, but the effects of this procedure on postoperative pain have been controversial. The first article regarding the effects of local anesthetic infiltration over the wound edge was by Coppelle in 1935 [13]. Mullen and Cook first reported that local anesthetic infiltration at the surgical wound decreased the severity of postoperative pain in patients who underwent lumbar discectomy [6-17]. They thought that this reduction in postoperative pain was caused by lessening of the psychological effect of lumbar surgery [14]. Perera et al. [4] conducted a systemic review and meta-analysis of local anesthetic infiltration use in lumbar spine surgery. Their review, which included 11 articles, reported that the severity of pain differed significantly between those who used local anesthetic and those in the control group at postoperative hour 1 , but not at 12 or 24 hours $(P=0.001, P=0.93$, and $P=0.85$, respectively) [4]. The 11 articles included one by Perera et al. [4] that included only patients who underwent lumbar discectomy and laminectomy.

There were three articles on lumbosacral fusion surgery that examined the relationship between local anesthetic infiltration and the severity of postoperative pain [4]. Bianconi et al. [16] reported that continuous local anesthetic infiltration was an effective method for postoperative pain control after posterior spine stabilization surgery. Xu et al. [17] conducted a study on the effects of continuous wound infiltration after thoracolumbar surgery (including fusion surgery), and showed that continuous wound infiltration with ropivacaine achieved a reduction of postoperative pain similar to that of intravenous analgesics; moreover, fewer complications related to analgesics drugs such as nausea, vomiting, and chronic pain were reported. Contrary to these articles, Greze et al. [18] reported that 

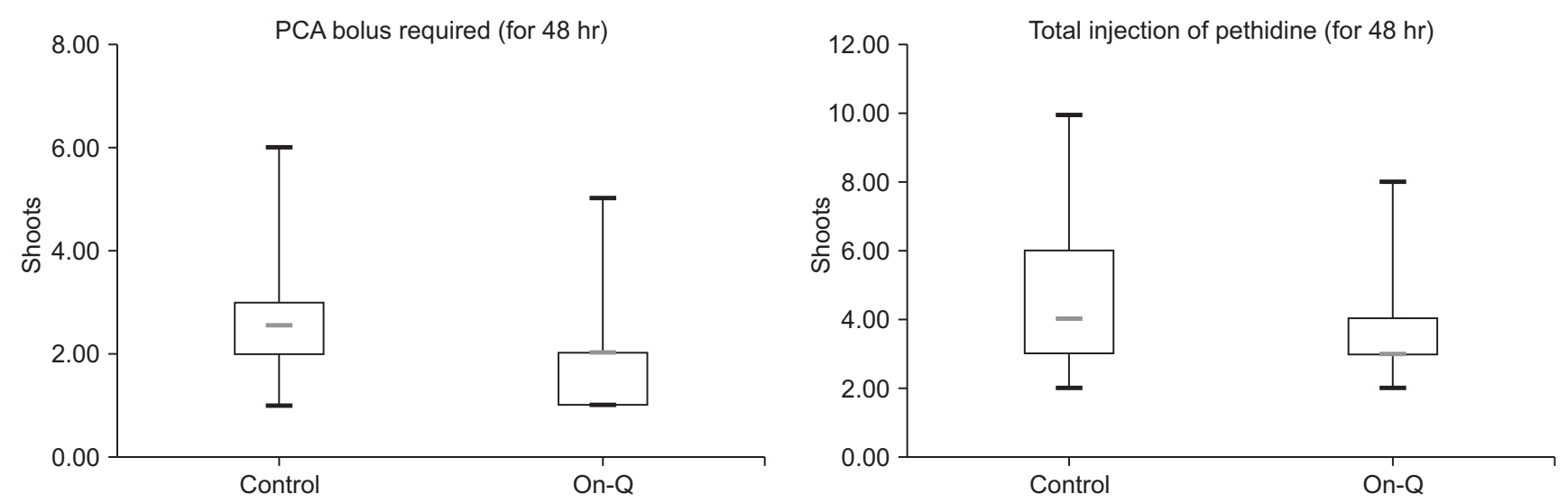

Fig. 3. Total postoperative patient-controlled analgesia (PCA) bolus and pethidine consumption in the postoperative 48 hours in the control $(n=30$ patients) and On-Q ( $n=31$ patients) groups. Boxplots show the interquartile range (box). There were statistical differences between the two groups $(P=0.049$, $P=0.032$ ).

continuous wound infiltration of ropivacaine after spinal fusion surgery did not provide additional analgesic effects compared to baseline multimodal agents.

In our study, continuous wound infiltration with ropivacaine after anterior lumbar fusion surgery effectively reduced postoperative pain at the abdominal site. As ours was the first study on the effectiveness of continuous infiltration with local anesthesia after ALIF surgery, large and prospective randomized studies are needed to further verify the effectiveness of this analgesic method. Moreover, the consumption of opioids in the postoperative 48 hours was lower in the On-Q group than in the control group. However, it should be noted that the effects of postoperative opioid consumption have being controversial. In a systematic review by Kjærgaard et al. [3] about wound infiltration with local anesthesia after decompression or discectomy, control patients consumed more opioids than patients receiving local anesthetics. A study by Greze et al. [18], on the effect of continuous wound infiltration after posterior fusion surgery, showed that the consumption of opioids during the postoperative 48 hours did not differ significantly between the trial and control groups. In a study by Bianconi et al. [16], continuous wound infiltration with ropivacaine significantly decreased the number of requests for other analgesics during the 72 hours after fusion surgery. As described above, effects related to a decrease in opioid consumption after local anesthetics infiltration has been controversial, but we think that this analgesic method may decrease the need for additional analgesics. In the future, we plan to conduct a prospective double-blinded randomized study on the effects of opioid consumption after continuous local anesthetics infiltration with ropivacaine.

There were only two articles, by Greeze et al. [18] and Milligan et al. [19], that reported the effect of postoperative wound infiltration with local analgesics. These articles showed no statistically significant differences between the trial and control groups regarding the time to the first mobilization after surgery. In contrast, our study reported that patients using the On-Q system were more active and performed activities such as sitting, standing, and walking sooner than those in the control group. We think that the On-Q system decreased postoperative pain at the abdominal site; this made it easier for patients to walk, sit, stand, etc.

Our study was the first to examine the effectiveness of continuous wound infiltration with ropivacaine after ALIF. There were some limitations. As this was a retrospective study, the enrolled patients had heterogeneous diseases, and the lengths of the surgical site differed among the patients. As such, a large-scale, prospective, randomized study is needed to evaluate the effectiveness of continuous wound infiltration with ropivacaine after ALIF surgery.

Our results revealed that continuous wound infiltration with ropivacaine using the On-Q system may be used to control postoperative pain after ALIF surgery. It may also lead to early mobilization, especially walking. Use of this method may prevent some of the potential side effects associated with reducing activities.

\section{CONFLICT OF INTEREST}

No potential conflict of interest relevant to this article was reported.

\section{FUNDING}

No funding to declare. 
Table 4. Performance state with assistance

\begin{tabular}{|c|c|c|c|}
\hline & On-Q (n= 31) & Control $(n=30)$ & $P$ value \\
\hline \multicolumn{4}{|c|}{ Ability to turn on bed } \\
\hline Pre OP & 31 (100.0) & 30 (100.0) & 0.999 \\
\hline Post OP & $10(32.3)$ & $8(26.7)$ & 0.632 \\
\hline Post $12 \mathrm{hr}$ & $24(77.4)$ & $24(80.0)$ & 0.806 \\
\hline Post 24 hr & $25(80.6)$ & $24(80.0)$ & 0.949 \\
\hline Post $48 \mathrm{hr}$ & $30(96.8)$ & 25 (83.3) & 0.104 \\
\hline Post 1 wk & $31(100.0)$ & $30(100.0)$ & 0.999 \\
\hline \multicolumn{4}{|l|}{ Ability to sit } \\
\hline Pre OP & 27 (87.1) & $29(96.7)$ & 0.173 \\
\hline Post OP & $10(32.3)$ & 10 (33.3) & 0.929 \\
\hline Post $12 \mathrm{hr}$ & $13(41.9)$ & 10 (33.3) & 0.488 \\
\hline Post $24 \mathrm{hr}$ & 18 (58.1) & $21(70.0)$ & 0.332 \\
\hline Post $48 \mathrm{hr}$ & $30(96.8)$ & $23(76.7)$ & 0.026 \\
\hline Post 1 wk & 31 (100.0) & 30 (100.0) & 0.999 \\
\hline \multicolumn{4}{|c|}{ Ability to get out bed } \\
\hline Pre OP & $30(96.8)$ & $29(96.7)$ & 0.981 \\
\hline Post OP & $9(29.0)$ & $10(33.3)$ & 0.717 \\
\hline Post $12 \mathrm{hr}$ & $10(32.3)$ & $12(40.0)$ & 0.529 \\
\hline Post 24 hr & $17(54.8)$ & $21(70.0)$ & 0.222 \\
\hline Post $48 \mathrm{hr}$ & $30(96.8)$ & $22(73.3)$ & 0.006 \\
\hline Post 1 wk & $30(96.8)$ & $30(100.0)$ & 0.999 \\
\hline \multicolumn{4}{|l|}{ Ability to stand } \\
\hline Pre OP & $30(96.8)$ & $29(96.7)$ & 0.981 \\
\hline Post OP & $10(32.3)$ & $10(33.3)$ & 0.929 \\
\hline Post $12 \mathrm{hr}$ & $10(32.3)$ & $12(40.0)$ & 0.529 \\
\hline Post $24 \mathrm{hr}$ & $29(93.5)$ & $20(66.7)$ & 0.008 \\
\hline Post $48 \mathrm{hr}$ & $30(96.8)$ & 28 (93.3) & 0.617 \\
\hline Post 1 wk & $30(96.8)$ & $30(100.0)$ & 0.999 \\
\hline \multicolumn{4}{|c|}{ Ability to use restroom } \\
\hline Pre OP & 27 (87.1) & $29(96.7)$ & 0.173 \\
\hline Post OP & $1(3.2)$ & $0(0.0)$ & 0.305 \\
\hline Post $12 \mathrm{hr}$ & $1(3.2)$ & $0(0.0)$ & 0.305 \\
\hline Post 24 hr & 20 (64.5) & $13(43.3)$ & 0.097 \\
\hline Post $48 \mathrm{hr}$ & 31 (100.0) & $24(80.0)$ & 0.011 \\
\hline Post 1 wk & $31(100.0)$ & $28(93.3)$ & 0.238 \\
\hline \multicolumn{4}{|c|}{ Ability to walk with walker } \\
\hline Pre OP & $19(61.3)$ & $21(70.0)$ & 0.474 \\
\hline Post OP & $0(0.0)$ & $0(0.0)$ & 0.999 \\
\hline Post $12 \mathrm{hr}$ & $6(19.4)$ & $5(16.7)$ & 0.785 \\
\hline Post $24 \mathrm{hr}$ & $22(71.0)$ & $16(53.3)$ & 0.155 \\
\hline Post $48 \mathrm{hr}$ & $30(96.8)$ & $23(76.7)$ & 0.020 \\
\hline Post 1 wk & $30(96.8)$ & $29(96.7)$ & 0.981 \\
\hline \multicolumn{4}{|c|}{ Ability to walk by self } \\
\hline Pre OP & $19(61.3)$ & $21(70.0)$ & 0.474 \\
\hline Post OP & $0(0.0)$ & $0(0.0)$ & 0.999 \\
\hline Post $12 \mathrm{hr}$ & $0(0.0)$ & $0(0.0)$ & 0.999 \\
\hline Post $24 \mathrm{hr}$ & $15(48.4)$ & $7(23.3)$ & 0.042 \\
\hline Post $48 \mathrm{hr}$ & $30(96.8)$ & $16(53.3)$ & 0.001 \\
\hline Post 1 wk & $30(96.8)$ & $29(96.7)$ & 0.981 \\
\hline \multicolumn{4}{|c|}{ Ability to walk above $100 \mathrm{~m}$} \\
\hline Pre OP & $12(38.7)$ & $11(36.7)$ & 0.869 \\
\hline Post OP & $0(0.0)$ & $0(0.0)$ & 0.999 \\
\hline Post $12 \mathrm{hr}$ & $0(0.0)$ & $0(0.0)$ & 0.999 \\
\hline Post $24 \mathrm{hr}$ & $14(45.2)$ & $12(40.0)$ & 0.684 \\
\hline Post $48 \mathrm{hr}$ & $28(90.3)$ & $20(66.7)$ & 0.024 \\
\hline Post 1 wk & 29 (93.5) & $23(76.7)$ & 0.081 \\
\hline
\end{tabular}

Values are presented as number (\%).

Pre: preoperative, Post: postoperative, OP: operation.
Table 5. Performance state by self

\begin{tabular}{|c|c|c|c|}
\hline & On-Q $(n=31)$ & Control $(n=30)$ & $P$ value \\
\hline \multicolumn{4}{|c|}{ Ability to turn on bed } \\
\hline Pre OP & 29 (93.5) & $29(96.7)$ & 0.573 \\
\hline Post OP & $3(9.7)$ & $2(6.7)$ & 0.668 \\
\hline Post $12 \mathrm{hr}$ & $14(45.2)$ & $10(33.3)$ & 0.344 \\
\hline Post $24 \mathrm{hr}$ & 25 (80.6) & 17 (56.7) & 0.043 \\
\hline Post $48 \mathrm{hr}$ & $30(96.8)$ & $19(63.3)$ & 0.001 \\
\hline Post 1 wk & $30(96.8)$ & $29(96.7)$ & 0.981 \\
\hline \multicolumn{4}{|l|}{ Ability to sit } \\
\hline Pre OP & 27 (87.1) & $29(96.7)$ & 0.173 \\
\hline Post OP & $0(0.0)$ & $0(0.0)$ & 0.999 \\
\hline Post $12 \mathrm{hr}$ & $0(0.0)$ & $0(0.0)$ & 0.999 \\
\hline Post $24 \mathrm{hr}$ & 5 (16.1) & $9(30.0)$ & 0.198 \\
\hline Post $48 \mathrm{hr}$ & 27 (87.1) & $19(63.3)$ & 0.031 \\
\hline Post 1 wk & $30(96.8)$ & $29(96.7)$ & 0.981 \\
\hline \multicolumn{4}{|c|}{ Ability to get out bed } \\
\hline Pre OP & $23(74.2)$ & $28(93.3)$ & 0.044 \\
\hline Post OP & $0(0.0)$ & $0(0.0)$ & 0.999 \\
\hline Post $12 \mathrm{hr}$ & $0(0.0)$ & $0(0.0)$ & 0.999 \\
\hline Post $24 \mathrm{hr}$ & $9(29.0)$ & 7 (23.3) & 0.613 \\
\hline Post $48 \mathrm{hr}$ & 29 (93.5) & 19 (63.3) & 0.004 \\
\hline Post 1 wk & $30(96.8)$ & $30(100.0)$ & 0.999 \\
\hline \multicolumn{4}{|l|}{ Ability to stand } \\
\hline Pre OP & $17(54.8)$ & $28(93.3)$ & 0.001 \\
\hline Post OP & $0(0.0)$ & $0(0.0)$ & 0.999 \\
\hline Post $12 \mathrm{hr}$ & $1(3.2)$ & $0(0.0)$ & 0.321 \\
\hline Post $24 \mathrm{hr}$ & $13(41.9)$ & $10(33.3)$ & 0.488 \\
\hline Post $48 \mathrm{hr}$ & $30(96.8)$ & $26(86.7)$ & 0.195 \\
\hline Post 1 wk & $30(96.8)$ & $24(80.0)$ & 0.178 \\
\hline \multicolumn{4}{|c|}{ Ability to use restroom } \\
\hline Pre OP & 18 (58.1) & $28(93.3)$ & 0.001 \\
\hline Post OP & $1(3.3)$ & $0(0.0)$ & 0.305 \\
\hline Post $12 \mathrm{hr}$ & $0(0.0)$ & $0(0.0)$ & 0.999 \\
\hline Post $24 \mathrm{hr}$ & $8(25.8)$ & $9(30.0)$ & 0.715 \\
\hline Post $48 \mathrm{hr}$ & $31(100.0)$ & $22(73.3)$ & 0.002 \\
\hline Post 1 wk & $29(93.5)$ & 27 (90.0) & 0.614 \\
\hline \multicolumn{4}{|c|}{ Ability to walk with walker } \\
\hline Pre OP & $16(51.6)$ & $19(63.3)$ & 0.355 \\
\hline Post OP & $0(0.0)$ & $2(6.7)$ & 0.144 \\
\hline Post $12 \mathrm{hr}$ & $0(0.0)$ & $0(0.0)$ & 0.999 \\
\hline Post $24 \mathrm{hr}$ & $8(25.8)$ & $12(40.0)$ & 0.238 \\
\hline Post $48 \mathrm{hr}$ & $30(96.8)$ & $22(73.3)$ & 0.002 \\
\hline Post 1 wk & $29(93.5)$ & $28(93.3)$ & 0.973 \\
\hline \multicolumn{4}{|c|}{ Ability to walk by self } \\
\hline Pre OP & $16(51.6)$ & $16(53.3)$ & 0.893 \\
\hline Post OP & $0(0.0)$ & $0(0.0)$ & 0.999 \\
\hline Post $12 \mathrm{hr}$ & $0(0.0)$ & $0(0.0)$ & 0.999 \\
\hline Post $24 \mathrm{hr}$ & $9(29.0)$ & $3(10.0)$ & 0.062 \\
\hline Post $48 \mathrm{hr}$ & 29 (93.5) & $13(43.3)$ & $<0.001$ \\
\hline Post 1 wk & 27 (87.1) & $24(80.0)$ & 0.679 \\
\hline \multicolumn{4}{|c|}{ Ability to walk above $100 \mathrm{~m}$} \\
\hline Pre OP & $8(25.8)$ & $6(20.0)$ & 0.590 \\
\hline Post OP & $0(0.0)$ & $0(0.0)$ & 0.999 \\
\hline Post $12 \mathrm{hr}$ & $0(0.0)$ & $0(0.0)$ & 0.999 \\
\hline Post $24 \mathrm{hr}$ & $9(29.0)$ & $9(30.0)$ & 0.934 \\
\hline Post $48 \mathrm{hr}$ & $28(90.3)$ & $18(60.0)$ & 0.006 \\
\hline Post 1 wk & $21(67.7)$ & $21(70.0)$ & 0.849 \\
\hline
\end{tabular}

Values are presented as number (\%).

Pre: preoperative, Post: postoperative, OP: operation. 


\section{ORCID}

Sang-Min Lee, https://orcid.org/0000-0002-2021-9128

Dong-Ju Yun, https://orcid.org/0000-0001-7074-0213

Sang-Ho Lee, https://orcid.org/0000-0002-8526-0260

Hyung-Chang Lee, https://orcid.org/0000-0001-5641-2475

Kyung Ho Joeng, https://orcid.org/0000-0002-1399-6316

\section{REFERENCES}

1. Ozyilmaz K, Ayoglu H, Okyay RD, Yurtlu S, Koksal B, Hanci $\mathrm{V}$, et al. Postoperative analgesic effects of wound infiltration with tramadol and levobupivacaine in lumbar disk surgeries. J Neurosurg Anesthesiol 2012; 24: 331-5.

2. Johansson B, Glise H, Hallerbäck B, Dalman P, Kristoffersson A. Preoperative local infiltration with ropivacaine for postoperative pain relief after cholecystectomy. Anesth Analg 1994; 78: 210-4.

3. Kjærgaard M, Møiniche S, Olsen KS. Wound infiltration with local anesthetics for post-operative pain relief in lumbar spine surgery: a systematic review. Acta Anaesthesiol Scand 2012; 56: 282-90.

4. Perera AP, Chari A, Kostusiak M, Khan AA, Luoma AM, Casey ATH. Intramuscular local anesthetic infiltration at closure for postoperative analgesia in lumbar spine surgery: a systematic review and meta-analysis. Spine (Phila Pa 1976) 2017; 42: 1088-95.

5. Phan K, Maharaj M, Assem Y, Mobbs RJ. Review of early clinical results and complications associated with oblique lumbar interbody fusion (OLIF). J Clin Neurosci 2016; 31: 23 9.

6. Beaussier M, Parc Y, Guechot J, Cachanado M, Rousseau A, Lescot T; CATCH Study Investigators. Ropivacaine preperitoneal wound infusion for pain relief and prevention of incisional hyperalgesia after laparoscopic colorectal surgery: a randomized, triple-arm, double-blind controlled evaluation vs intravenous lidocaine infusion, the CATCH study. Colorectal Dis 2018; 20: 509-19.

7. Fassoulaki A, Vassi E, Korkolis D, Zotou M. Perioperative continuous ropivacaine wound infusion in laparoscopic cholecystectomy: a randomized controlled double-blind trial. Surg Laparosc Endosc Percutan Tech 2016; 26: 25-30.

8. Mungroop TH, Veelo DP, Busch OR, van Dieren S, van Gulik TM, Karsten TM, et al. Continuous wound infiltration versus epidural analgesia after hepato-pancreato-biliary surgery (POP-UP): a randomised controlled, open-label, non-inferiority trial. Lancet Gastroenterol Hepatol 2016; 1: 105-13.

9. Reinikainen M, Syväoja S, Hara K. Continuous wound infiltration with ropivacaine for analgesia after caesarean section: a randomised, placebo-controlled trial. Acta Anaesthesiol Scand 2014; 58: 973-9.

10. Mitra S, Purohit S, Sharma M. Postoperative analgesia after wound infiltration with tramadol and dexmedetomidine as an adjuvant to ropivacaine for lumbar discectomies: a randomized-controlled clinical trial. J Neurosurg Anesthesiol 2017; 29: 433-8.

11. Hopf HW, Hunt TK, West JM, Blomquist P, Goodson WH 3rd, Jensen JA, et al. Wound tissue oxygen tension predicts the risk of wound infection in surgical patients. Arch Surg 1997; 132: 997-1004.

12. Woolf CJ, Chong MS. Preemptive analgesia--treating postoperative pain by preventing the establishment of central sensitization. Anesth Analg 1993; 77: 362-79.

13. Knudsen K, Beckman Suurküla M, Blomberg S, Sjövall J, Edvardsson N. Central nervous and cardiovascular effects of i.v. infusions of ropivacaine, bupivacaine and placebo in volunteers. Br J Anaesth 1997; 78: 507-14.

14. Ford GT, Guenter CA. Toward prevention of postoperative pulmonary complications. Am Rev Respir Dis 1984; 130: 4-5.

15. Mullen JB, Cook WA Jr. Reduction of postoperative lumbar hemilaminectomy pain with Marcaine. Technical note. J Neurosurg 1979; 51: 126-7.

16. Bianconi M, Ferraro L, Ricci R, Zanoli G, Antonelli T, Giulia B, et al. The pharmacokinetics and efficacy of ropivacaine continuous wound instillation after spine fusion surgery. Anesth Analg 2004; 98: 166-72.

17. Xu B, Ren L, Tu W, Wu Z, Ai F, Zhou D, et al. Continuous wound infusion of ropivacaine for the control of pain after thoracolumbar spinal surgery: a randomized clinical trial. Eur Spine J 2017; 26: 825-31.

18. Greze J, Vighetti A, Incagnoli P, Quesada JL, Albaladejo P, Palombi $\mathrm{O}$, et al. Does continuous wound infiltration enhance baseline intravenous multimodal analgesia after posterior spinal fusion surgery? A randomized, double-blinded, placebo-controlled study. Eur Spine J 2017; 26: 832-9.

19. Milligan KR, Macafee AL, Fogarty DJ, Wallace RG, Ramsey P. Intraoperative bupivacaine diminishes pain after lumbar discectomy. A randomised double-blind study. J Bone Joint Surg Br 1993; 75: 769-71. 